Volker Leppin

\title{
Geschichte des mittelalterlichen Christentums
}

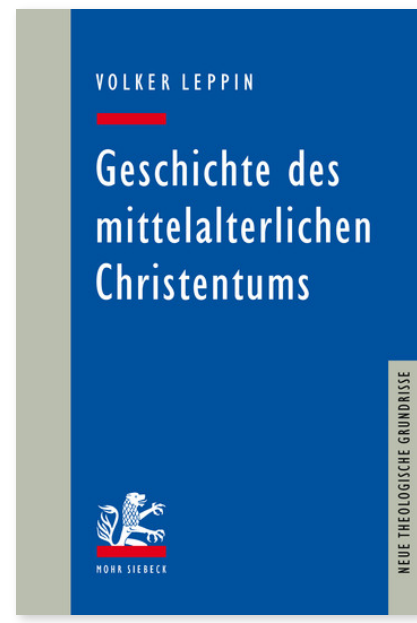

2012. XV, 459 Seiten. NThG

ISBN 978-3-16-152098-3

eBook PDF $89,00 €$

ISBN 978-3-16-150677-2

fadengeheftete Broschur 39,00€

ISBN 978-3-16-151709-9

Leinen $89,00 €$
Rund hundert Jahre nach dem großen Überblick von Albert Hauck erscheint wieder eine Darstellung des mittelalterlichen Christentums aus der Feder eines evangelischen Kirchenhistorikers. Das kirchliche Geschehen wird darin, mit einem besonderen Blick auf Theologie und Frömmigkeit, in die allgemeine Entwicklung Europas eingeordnet. Volker Leppin zeichnet in diesem Werk den Gang des Christentums von den Umbrüchen durch Völkerwanderung bzw. Ethnogenese über die hochmittelalterlichen Verfestigungen und Ausdifferenzierungen bis in das späte Mittelalter mit seinen vielfältigen Spannungen und Polaritäten nach. Dabei werden Prägungen durch das christliche Zeichensystem ebenso berücksichtigt wie die Entstehung weltlicher Werthorizonte, wie sie sich etwa in adeligen und bürgerlichen Welten des hohen und späten Mittelalters nachvollziehen lassen. Die Ereignisse in Deutschland mit dem paradigmatischen Gegenüber von Kaiser und Papst werden in den europäischen Gesamtzusammenhang eingestellt, in dem insbesondere England und Frankreich als Mächte erscheinen, die die Kirchengeschichte mitgestalteten. Der Autor bietet umfassende Informationen über die äußeren Ereignisse auf dem Stand der aktuellen interdisziplinären Forschung. Kirchengeschichte ist damit zugleich auch eine Kulturgeschichte des Christentums.

Für Bibliotheken gelten bei diesem Titel abweichende Konditionen; bitte wenden Sie sich an den Vertrieb.

Volker Leppin Geboren 1966: Studium der Ev. Theologie; 1994 Promotion; 1997 Habilitation; 2000-10 Lehrstuhl für Kirchengeschichte in Jena; 2010-21 Lehrstuhlinhaber für Kirchengeschichte in Tübingen; seit 2021 Horace Tracy Pitkin Professor of Historical Theology an der Yale Divinity School.

https://orcid.org/0000-0001-8561-1086
Jetzt bestellen:

https://mohrsiebeck.com/buch/geschichte-des-mittelalterlichen-christentums-9783161520983?no_cache=1 order@mohrsiebeck.com

Telefon: $+49(0) 7071-923-17$

Telefax: $+49(0) 7071-51104$ 